\title{
Technical and economic evaluation of justification for preventing negative effects of feedback in local elements of interaction of rail yards
}

\author{
Petro Yanovsky ${ }^{1}$, Sergiy Lytvynenko ${ }^{2}$, Larysa Lytvynenko ${ }^{3}$, and Volodymyr Tkachenko ${ }^{1}$ \\ ${ }^{1}$ National Aviation University, Military Training Department, 03058 Kyiv, Ukraine \\ ${ }^{2}$ National Aviation University, International Economy Department, 03058 Kyiv, Ukraine \\ ${ }^{3}$ National Aviation University, Management of Foreign Economic Activity of Enterprises Department, 03058 Kyiv, Ukraine
}

\begin{abstract}
The operation of rail yards is characterized not only by direct links, but also by feedback in the local elements of interaction, resulting in a violation of interaction conditions between adjacent elements, which causes a negative effect on the state and functioning of the elements. The duration of the track occupation in the arrival yard depends on both its parameters: the marshalling hump and the operation of other elements of the yard located at the arrival yard in the direction of cargo traffic processing. Therefore, when choosing the rational parameters of the rail yards, attention should be paid to the existence of feedbacks in the local elements of interaction and conditions of their negative manifestation should be investigated in order to justify measures to eliminate them. In the article, the issue of improving the customer transport service quality by technical and technological modernization of railway enterprises was studied. Technical and economic evaluation on justification of measures for the elimination of negative effects of feedback in local elements of interaction of the rail yards is presented for practical use.
\end{abstract}

\section{Introduction}

The operation of rail yards is characterized by action of direct links and feedback in the local elements of interaction (LEI) resulting in a violation of interaction terms between adjacent elements arises, which has negative effect on the state and operation of the elements.

For example, it was determined that the duration of track occupation in the arrival yard depends on its parameters and parameters of the marshalling hump, but also on the functioning of other elements of the yard located at the arrival yard according to the direction of the railway car traffic processing. So, when selecting rational parameters of the rail yards, the feedback in the LEI should be taken into account and conditions should be studied for its negative manifestation aimed at justifying measures on its elimination.

Such research should begin with the departure yard (DY), where the duration of staying of trains is influenced by the following factors: capacity of adjacent sections, the intensity of locomotive conveyance to trains, the intensity of servicing trains by inspection station brigades and the number of tracks in the departure yard.

\section{Literature review and defining the problem}

Transport production is a solid basis of the market economy and ensures the efficient functioning and development of all economic sectors serviced by transport as a market relations subject in a state with qualitative activity. Economic development is provided by the rational interaction of railways and industrial enterprises in the context of establishing mutually beneficial economic and legal relations between transport and cargo owners. Thus, compromise management of the transport process is carried out on equal participation of all its participants, as a result of which the highest social effect of the production and economic activity of subjects of different ownership forms and size (large, medium or small business) is ensured in the state.

The peculiarities of transport production, as a multi-aspect issue, have been constantly studied in our country and abroad. Important results of such studies are published in the scientific works of F. Kochnev, M. Pravdin, M. Fedotov, M. Galatchenko, M. Stefanov, V. Negrey, I. Tikhomirov, M. Ilovaysky, J. Kulayev, N. Tereshina, A. Smekhova, S.

\footnotetext{
* Corresponding author: sllitvinenko1982@gmail.com
} 
Razer, D. Lomotko, E. Nagorny, V. Shish, A. Kotenko, T. Butko, E. Alyoshinskyi, D. Kozachenko, V. Mironenko, V. Samsonkin and others.

Issues of reducing the cargo delivery duration by rail through decreasing the train procession time at border transfer stations were studied by Ye. Aloshynskyi, V. Naumov and O. Pestremenko-Skripka [1], resulting in offering risk management systems based on the selective survey operations principle to solve the problem.

In the paper [2] Ye. Aloshynskyi, H. Prymachenko and Yu. Shuldiner analyzed another aspect of improvement: basic directions of increasing the level of logistics principles implementation in Ukrainian conditions. Also, D. Lomotko, Ye. Aloshynskyi and G. Zambrybor [3] have come to the conclusion that methodological aspect of the logistics technologies formation in reforming processes on the railways is related to system-wide optimization providing synergy effect and considering the complex of all participants' interests in the transportation process.

An automated traffic capacity calculation method taking into account the operating reliability of the rail transportation system was developed by S. Panchenko, T. Butko, A. Prokhorchenko, L. Parkhomenko to increase the efficiency of transport logistics and ensuring more accurate evaluation of rational workload limits of a rail network [4].

T. Butko and O. Shander in [5] developed mathematical model formalizing the technological process of managing the cargo transportation fleet of operator companies which was solved with the use of mathematical apparatus of genetic algorithms.

Some aspects of the efficiency increase of the transportation process of the railway directions by improving the operational management of the locomotive fleet operation were considered by L. Yelnikova [6]. The study is focused on solving the task of developing an operational plan for railway locomotive fleet as a multi-criteria assignment problem.

In the transport process, in addition to manufacturing enterprises, workers of various railways structures are involved, whose activity is aimed at solving of one common task for the economy - the safe and high-quality transportation of passengers and cargoes. All components of a complex multi-sectoral railway system should work in a close interaction with each other. This over-complex task is constantly being studied by domestic scientists and practitioners. However, the introduction into the national economy of market relations reveal previously under-studied aspects of operation activity of railways in modern economic conditions in a new way, requiring the continuation of carrying out $\mathrm{R} \& \mathrm{D}$ in this direction.

\section{Research aim and objectives}

The purpose of the article is the development of methodical recommendations on the feasibility study of measures to prevent the negative effects of feedback in the local elements of interaction (LEI) of the rail yards. In general, the optimum mode of the rail yard is provided by the high level of operating technology and technical equipment of individual LEI, due to their precise interaction and coherence. Such a level of interoperability of all LEI of a specific yard can be achieved by the introduction of effective measures the economic feasibility of which is justified using given methodical guidelines.

\section{Overview key findings}

\subsection{Detection and systematization of the feedback negative influence factors in local elements of rail yards' interaction}

Under the specific operating conditions, it is necessary to identify and systematize all factors by their degree of action, revealing among them the most influential ones, in order to concentrate the main attention, as well as, if necessary, financial resources on them.

Then the state and features of LEI functioning should be analyzed (moving towards the processed railway car traffic): output sections (OS), departure yard (DY), dead-end tracks (DET), maneuver locomotives (ML), marshalling bay (MB), marshalling hump (MH), arrival yard (AY), inlet sections (IS). Such a back review of LEI will provide an opportunity to study feedbacks in detail and predict measures implementation of which eliminates their negative effect.

The total annual costs of the rail yard caused by the negative effect of feedback in LEI due to the increase in downtimes of trains in the station yards are determined by the formula:

$$
\mathrm{E}_{c}=365 \cdot m\left[\Delta t_{d c}\left(N_{t r}+N_{f}\right)+\Delta t_{f} N_{f}+t_{a y} N_{d i s}\right] C_{c-h},
$$

where $m$ - average number of railway cars in the train; $\Delta t_{d c}$ - average additional downtime of railway cars in the departure yard (DY) caused by the violation of the conditions in interaction of DY with adjacent sections; $N_{t r}+N_{f}-$ total number of trains departing from DY to all adjacent sections (transit and its formation); $\Delta t_{f}-$ average additional downtime of railway cars in the marshalling bay (MB) caused by the violation of the conditions in interaction between stretches of formation (SF) and the departure yard (DY); $N_{f}$-number of formation trains; $t_{a y}$ - average additional downtime of railway cars in the arrival yard (AY) caused by the violation of the conditions in interaction of marshalling 
hump (MH) and marshalling bay (MB); $N_{d i s}$-number of trains arriving to disassembling; $C_{c-h}-$ present value of one downtime railway car-hour.

In the conditions of market transformations in Ukraine there is a significant shortage of financial resources. For the purpose of their rational use it is necessary to invest them in the most effective and important measures for accelerating the passage of railway cars through the rail yard. Therefore, in such difficult economic conditions it is important to identify rational implementation phasing of measures from a possible list. In addition, any acceleration in the turnover of railway cars gives positive benefits to cargo owners in terms of cargo delivery, and costs are borne by the railways. Unfortunately, the cooperation of railways and a number of clients is not yet based on the partnership principles with the implementation of compromise solutions. It's time to decide on a fair distribution of the non-transport effect among all the participants in the transport process at scientific and technical levels. But so far, railways are forced to solve their own problems independently without the help of authorities and business. Public administration bodies should change the consumer attitude to railway transport, the state of which is currently catastrophic [7]:

- share of main roads with overdue major repairs $-27 \%$;

- $78 \%$ of road vehicles has expired service life;

- deterioration of traction sub-stations is $67 \%$ and contact network $-65 \%$;

- deterioration of main electric locomotives is $92 \%$ and their operating fleet $--66 \%$ of the inventory;

- deterioration of main diesel locomotive is $99 \%$ and their operating fleet $-42 \%$ of the inventory;

- deterioration of maneuver diesel locomotives is over $80 \%$ and their operating fleet - $62 \%$ of the inventory;

- deterioration of cargo railway cars is more than $90 \%$ and their operating fleet $-64 \%$ of the inventory;

- deterioration of passenger railway cars exceeds $87 \%$ and their operating fleet $-66 \%$ of the inventory;

- deterioration of electric and diesel trains is over $90 \%$ and their operating fleet $-79 \%$.

These negative phenomena should be also complement by the permanent worsening of staffing of the transport process - the number of dismissed railway workers is increasing due to very low salaries and practical absence of the social protection system and provision of adequate working conditions. The average salary in Ukraine is the lowest in Europe (€190), which is 2.5 times less than in Russia and 24 times less than in Switzerland.

It is also worth mentioning the lowest (non-market) tariffs for cargo transportation in Europe and the unfair charges for the use of railway cars. Taking into account the given data, authorities should radically change the attitude towards the railway transport and to stop investing big business at its expense by introducing the transport process compromise management system (TPCMS) into the economy.

\subsection{Determination of the optimal mode of rail yard operation}

The optimal mode of rail yard operation is determined by one of the options of the operation organization and technical equipment of individual local elements of interaction, for which total present costs will be minimal [8-11]. If violations of interaction between the rail yard's adjacent local elements of interaction and the acute shortage of finances in determining the rational phasing of enhancing technical equipment and improvement of the elements' technology were suspected, it is desirable to comply with the following terms (in the implementation of measures for the development of LEI):

$$
E_{c} \geq E_{d y}+E_{f}+E_{m b}+E_{a y},
$$

where $E_{d y}$ - total annual costs of the departure yard; $E_{f}$ - total annual costs of the formation subsystem; $E_{m b}-$ total annual costs of the marshalling bay; $E_{a y}$ - total annual costs of the arrival yard.

According to the results of the analysis [6], at rail yards average downtime of trains waiting for train locomotives in the departure yard exceeds 1.5 hours and is up to 3 or more hours, negatively affecting the operation of all previous elements of rail yards right the way to the arrival yard. Also, it is worth pointing out that part of the waiting time of a train locomotive in the total downtime of railway cars at rail yards ranges from $10 \%$ to $60 \%$ depending on the category of cars (with processing, without processing).

It should be noted that in justifying specific measures for the development of individual LEI under condition (2) it will not be possible to foresee simultaneous improvement of all elements of the rail yard. Therefore, the realistic option is the allocation of financial resources for improving equipment and technology only for the development of individual elements, starting with the train departure subsystems.

\subsection{Methodology for determining costs of implementing measures for the development of individual LEI}

Consequently, it is necessary to determine costs for the implementation of each measure separately. Additional number of train locomotives required for the removal of prepared trains from the rail yard delayed during the period due to violation of the condition in interaction between the departure yard and adjacent sections (the shortage of train locomotives) is determined by the formula:

$$
\Delta M=\Delta N \cdot K_{n},
$$


where $\Delta N$ - the number of trains delayed in the departure yard per year during periods $\Delta t_{l}^{a}$ due to absence of train locomotives; $K_{n}$ - the coefficient of locomotive needs for a pair of trains:

$$
K_{n}=\frac{1}{24}\left(\frac{2 l}{v_{g}}+t_{y}^{\prime}+t_{y}^{\prime \prime}\right),
$$

where $l$ - length of the design-section; $v_{g}$ - sectional speed on the design-section; $t_{y}^{\prime}, t_{y}^{\prime \prime}$ - average time of finding locomotives at yards limiting the design-section.

Increased investments in a locomotive fleet are determined by the formula:

$$
\Delta I_{l}=C_{l} \cdot \Delta M \cdot \alpha_{l},
$$

where $C_{l}$ - cost of one train locomotive; $\alpha_{l}$ - coefficient taking into consideration the location of locomotives in repair and costs associated with the locomotive development.

Costs of purchasing additional locomotives and their maintenance are determined by the formula:

$$
E_{d y}^{l}=\frac{\Delta I_{l}}{t_{p p}}+\Delta \mathrm{B}_{d}^{l}
$$

where $t_{p p}$ - normative payback period; $\Delta \mathrm{B}_{d}^{l}$ - additional running costs for the maintenance of additional locomotives and related devices per year.

If needed to increase the inspection station staff, costs on salary are determined by the formula:

$$
\mathrm{E}_{d y}^{b r}=12 \cdot t_{s} \cdot n_{s} \cdot x \cdot S \cdot C_{m o n}^{g r}
$$

where $t_{s}$ - duration of one shift (12 hours); $n_{s}$ - number of shifts $(4,5) ; x$ - number of groups in the brigade; $S-$ number of brigades; $C_{m o n}^{g r}-$ salary of one group of inspection station employees per month.

In case of insufficient number of tracks in the departure yard, annual costs of track-laying and maintenance of additional tracks are determined by the formula:

$$
E_{d y}^{t}=\Delta Q_{d y}\left(\frac{I_{t}}{t_{r r}}+c_{d}^{t}\right),
$$

where $\Delta Q_{d y}$ - number of additional tracks in the departure yard necessary to eliminate delays in the formation of trains from marshalling bay; $I_{t}$ - capital costs for laying one track with all necessary devices; $c_{d}^{t}-$ running costs of maintaining one track and necessary devices per year.

Moreover, it is necessary to take into account the costs associated with railway cars' downtimes in the departure yard under technological operations and in waiting for their execution as follows:

$$
E_{d y}^{d}=365 \cdot m \cdot t_{d y}\left(N_{t r}+N_{f}\right) C_{c-h}
$$

where $t_{d y}$ - average duration of trains' downtimes in the departure yard.

Total annual present costs for the implementation of all measures to eliminate additional trains' downtimes in the departure yard due to violation of the conditions in interaction of adjacent elements are calculated by the formula:

$$
E_{d y}=E_{d y}^{l}+E_{d y}^{b r}+E_{d y}^{t}+E_{d y}^{d}
$$

When carrying out technical and economic calculations, it is necessary to take into account the restrictions on loading of all elements of the yard (not more than 100\%).

At various rail yards the amounts of maneuver stretches and shunting locomotives are not the same that affects the time of railway cars being in the train formation subsystem. Annual costs for the construction and maintenance of maneuver stretch, and for the purchase and maintenance of shunting locomotives are determined by the formula:

$$
E_{e f}^{e l}=\frac{\Delta Q_{e f} \cdot I_{e f}+\Delta M_{m a n} \cdot C_{m a n}}{t_{r r}}+\Delta Q_{e f} \cdot b_{e f}+\Delta M_{\text {man }} \cdot b_{\text {man }},
$$

where $\Delta Q_{e f}$ - additional required number of maneuver stretches; $I_{e f}$ - capital costs for the construction of one exhaust track; $\Delta M_{\text {man }}$ - additional required number of shunting locomotives; $b_{e f}$ - costs of maintaining one maneuvering track; $C_{\text {man }}$ - cost of one shunting locomotive; $b_{\text {man }}$ - costs of maintaining one shunting locomotive.

Annual costs related to the railway cars' downtime in the train formation subsystem: 


$$
E_{e f}^{d}=365 \cdot m \cdot N_{t f} \cdot t_{t f} \cdot C_{c-h},
$$

where $t_{t f}$-average duration of a train being in the train formation subsystem.

Then total annual costs of in the train formation subsystem amount to:

$$
E_{e f}=E_{e f}^{e l}+E_{e f}^{d} .
$$

Rail yards have different number of tracks in the marshalling bay. In addition, the average duration of prepared trains being on marshalling tracks may vary.

In cases when there is a need to increase the number of tracks in the marshalling bay to provide a high level of interaction between the elements of rail yards, costs of their construction and maintenance will be:

$$
E_{m b}^{t}=\Delta Q_{m b}\left(\frac{I_{m t}}{t_{r r}}+c_{d}^{t}\right),
$$

where $\Delta Q_{m b}$ - required number of additional tracks in the marshalling bay; $I_{m t}$ - costs of construction of one marshalling track; $c_{d}^{t}$ - running costs for the maintenance one marshalling track.

Costs of to railway cars' downtimes in the marshalling bay after their accumulation due to waiting formation and relocating of trains to the departure yard are determined by the formula:

$$
E_{m b}^{d}=365 \cdot m \cdot N_{f} \cdot t_{w}^{f \cdot d} \cdot C_{c-h}
$$

where $t_{w}^{f . d}$ - average downtime of one train in the marshalling bay waiting formation and relocating to the departure yard.

Total annual costs of the marshalling bay amount to:

$$
E_{m b}=E_{m b}^{t}+E_{m b}^{d}
$$

At rail yards marshalling humps have different technical equipment and differences in the operating technology reflected in the value of the important marshalling hump's operating indicator - marshalling hump interval $t_{m h}$. The duration of railway cars being in the arrival yard is affected by the number of tracks, the technology of technical maintenance of railway cars by the inspection station brigade, the intensity of dismantling of trains in the marshalling hump. Therefore, the list of options for the technology of the arrival yard's and its technical equipment's operation is formed depending on the above mentioned factors.

Costs of salaries of inspection station brigades $E_{a y}^{b r}$ is calculated by the formula (7), and costs of technical equipment of the marshalling hump $E_{m h}$ - by the formula which is similar to the dependency (14).

To determine costs of building additional tracks in the arrival yard $E_{a y}^{t}$ the formula (14) is applied, and costs of downtime of railway cars in the arrival yard $E_{a y}^{d}$ - dependency (15). Then, total costs for the implementation of measures to improve the technical equipment and operating technology of the arrival yard and marshalling hump can be calculated as follows:

$$
E_{s . m h}=E_{a y}^{b r}+E_{m h}+E_{a y}^{t}+E_{a y}^{d}
$$

\subsection{Discussion of research findings}

Thus, when selecting the optimal option of organizing of the rail yard's operation and reducing the influence of violations of the conditions in interaction between the adjacent local elements of interaction (LEI) on the operation of elements of the yard, it is necessary to take into account the variability of delivery of railway cars, as well as differences in technical equipment and technologies of rail yards. Moreover, it is also important to consider both direct and indirect mutual effects of parameters of yard elements.

In modern conditions of sharp reduction in loading of rail yards during a prolonged economic crisis will not require the need to perform technical and economic calculations to determine the cost of implementing all the activities listed in the research. Probably, it will be enough to calculate only one or maximum several measures to improve the feedback interaction of adjacent LEI.

\section{Conclusions}

The railway transport plays especially important role in market transformations of the state and has a significant impact on the proper functioning of industrial enterprises and agriculture. It is very important in providing foreign economic 
relations and defense of the state. At present the railway transport has the task of comprehensive development, speeding turnover of railway cars, increasing the speed of trains, compliance with the train schedule and ensuring the cargo and passenger transportation safety. These requirements are extremely urgent for the railways in the face of a large deficit in financial resources.

Serious technical condition of the infrastructure and the rolling stock of railways require a radical change in the attitude of public authorities towards solving these issues. To resolve them, it is necessary to provide the railways with the right to fairly earn money for their operation at the legislative level. First and foremost, it is urgent to introduce a market tariff system and payment for the use of railway cars. The railway transport needs to be transformed into a full partner in the economic system of the state through introduction of the transport process compromise management system and termination of investing large business at the expense of the railway transport. The implementation of such a statesmanship to the solution of the transport problem in Ukraine will enable railways to not only urgently carry out technical and technological modernization, but also to resolve an extremely important staffing issue by substantially raising salaries for employees not less than three times. Thereby, the financial state improvement will enable railways to reasonably make progressive decisions on their own development using the designed methodical recommendations, which will significantly improve the quality of transport servicing of national economy.

\section{References}

1. Ye. Aloshynskyi, V. Naumov, O. Pestremenko-Skripka, Technical Transaction. Civil Engineering, 6: 43-54 (2018)

2. Ye. Aloshynskyi, H. Prymachenko, Yu. Shuldiner, Perspectives of Science and Education, 1: 5-12 (2018)

3. D. Lomotko, Ye. Aloshynskyi, G. Zambrybor, Transportation Research Procedia, 14: 2762-2766 (2016)

4. S. Panchenko, T. Butko, A. Prokhorchenko, L. Parkhomenko, Scientific Bulletin of National Mining University, 2: 93-98 (2016)

5. T. Butko, O. Shander, Eastern-European Journal of Enterprise Technologies, 2/3, 68: 55-58 (2014)

6. L. Yelnikova. The efficiency increase of the transportation process of the railway directions by improving the operational management of the locomotive park operation. Dnipropetrovsk: Dnipro National University of Railway Transport named after academician V. Lazaryan (2016) http://eadnurt.diit.edu.ua/bitstream/123456789/4713/1/aref Yelnikova\%20.PDF

7. Development Strategy of PJSC "Ukrzaliznytsya" for 2017-2021 [Online] from http://cfts.org.ua/files/ Session 1 Kravtsov.pdf [Accessed on 27 May 2019]

8. P.E. Chestnov. Railway Transport, 9: 64-65 (2013)

9. A.I. Verlin, N.I. Berezovyiy, R.V. Vernigora, A.M. Shepeta, Transport systems and transportation technologies, 3: 15-19 (2012)

10. P.O. Yanovsky, G.G. Volkovska, Transport systems and transportation technologies, 4: 103-108 (2012)

11. P.O. Yanovsky, Railway transport of Ukraine, 1: 41-49 (2014) 